\title{
Pax4 is not essential for beta-cell differentiation in zebrafish embryos but modulates alpha-cell generation by repressing arx gene expression
}

Joachim Djiotsa', Vincianne Verbruggen ${ }^{1}$, Jean Giacomotto ${ }^{2}$, Minaka Ishibashi², Elisabeth Manning ${ }^{2}$, Silke Rinkwitz ${ }^{2}$, Isabelle Manfroid ${ }^{1}$, Marianne $L$ Voz ${ }^{1}$ and Bernard Peers ${ }^{1 *}$

\begin{abstract}
Background: Genetic studies in mouse have demonstrated the crucial function of PAX4 in pancreatic cell differentiation. This transcription factor specifies $\beta$ - and $\delta$-cell fate at the expense of a-cell identity by repressing $\operatorname{Arx}$ gene expression and ectopic expression of PAX4 in a-cells is sufficient to convert them into $\beta$-cells. Surprisingly, no Pax4 orthologous gene can be found in chicken and Xenopus tropicalis raising the question of the function of pax4 gene in lower vertebrates such as in fish. In the present study, we have analyzed the expression and the function of the orthologous pax4 gene in zebrafish.

Results: pax4 gene is transiently expressed in the pancreas of zebrafish embryos and is mostly restricted to endocrine precursors as well as to some differentiating $\delta$ - and $\varepsilon$-cells but was not detected in differentiating $\beta$-cells. pax4 knock-down in zebrafish embryos caused a significant increase in a-cells number while having no apparent effect on $\beta$ - and $\delta$-cell differentiation. This rise of a-cells is due to an up-regulation of the Arx transcription factor. Conversely, knock-down of arx caused to a complete loss of a-cells and a concomitant increase of pax4 expression but had no effect on the number of $\beta$ - and $\delta$-cells. In addition to the mutual repression between Arx and Pax4, these two transcription factors negatively regulate the transcription of their own gene. Interestingly, disruption of pax4 RNA splicing or of arx RNA splicing by morpholinos targeting exon-intron junction sites caused a blockage of the altered transcripts in cell nuclei allowing an easy characterization of the arx-and pax4-deficient cells. Such analyses demonstrated that arx knock-down in zebrafish does not lead to a switch of cell fate, as reported in mouse, but rather blocks the cells in their differentiation process towards a-cells.
\end{abstract}

Conclusions: In zebrafish, pax4 is not required for the generation of the first $\beta$ - and $\delta$-cells deriving from the dorsal pancreatic bud, unlike its crucial role in the differentiation of these cell types in mouse. On the other hand, the mutual repression between Arx and Pax4 is observed in both mouse and zebrafish. These data suggests that the main original function of Pax4 during vertebrate evolution was to modulate the number of pancreatic a-cells and its role in $\beta$-cells differentiation appeared later in vertebrate evolution.

Keywords: Insulin, Glucagon, Pancreas, pax4, Arx, mRNA export, Development, Zebrafish

\footnotetext{
* Correspondence: Bpeers@ulg.ac.be

${ }^{1}$ From Unit of Molecular Biology and Genetic Engineering, Giga-Research, University of Liège, 1 avenue de l'Hôpital B34, Sart-Tilman B-4000, Belgium Full list of author information is available at the end of the article
} 


\section{Background}

In vertebrates, the pancreas plays a fundamental role in nutritional homeostasis through the secretion of various enzymes and hormones by acinar and endocrine cells, respectively. The endocrine cells form aggregates, called islets of Langerhans, and are composed of five cell subtypes $(\alpha-, \beta-, \delta-, \varepsilon-$ and PP-cells) each producing a distinct hormone (glucagon, insulin, somatostatin, ghrelin and pancreatic polypeptide, respectively). All endocrine pancreatic cells differentiate during embryogenesis from progenitor cells specified in the dorsal and the ventral pancreatic buds, two protrusions that emerge from the endodermal embryonic gut [1]. This differentiation process is controlled by a panoply of transcription factors [2,3], such as PDX1 and PTF1a acting at early stages to specify the pancreatic progenitors [4-6], then the HLH factors NGN3 and NEUROD inducing the endocrine precursors $[7,8]$, and the homeodomain factors NKX2.2, NKX6.1, PAX6, PAX4 and ARX controlling the formation of the five endocrine cell subtypes [9-14].

In mouse embryos, Pax4 gene expression first appears in endocrine precursors and then is detected transiently in numerous differentiating $\beta$-cells and occasional $\alpha$ cells $[15,16]$. Pax4 expression seems to switch off upon terminal $\beta$-cell maturation $[17,18]$, although some studies have reported expression in adult $\beta$-cells $[19,20]$. PAX4 has at least two functions in the differentiation of murine pancreatic cells. First, it favours the fate of the endocrine precursors toward the $\beta$ - and $\delta$-cell fate while repressing the $\alpha$-cell lineage. Indeed, Pax4 mutant mice display a lack of $\delta$-cells, an almost complete loss of $\beta$ cells and an increase in $\alpha$-cells [10]. This first role is due, at least in part, to the repression by PAX4 of the Arx gene, which encodes for an aristaless homeodomain factor and is absolutely required for the differentiation of $\alpha$-cells [12]. Inversely, ARX is also able to repress Pax4 gene expression and the Arx mutant mice have no $\alpha$-cells and an increase of $\beta$-and $\delta$-cells. So, the balance of $\alpha$-cells versus $\beta-/ \delta$-cells in pancreatic islets is controlled in mouse by an antagonistic action of the two homeodomain factors ARX and PAX4. While PAX4 favours the $\delta$ - and $\beta$-cell fate, it has no role per se in $\delta$ cell differentiation; indeed, the double Arx-/-; Pax4-/mice have no $\alpha$ - and almost no $\beta$-cells but display a strong increase in $\delta$-cells [21]. Furthermore, ectopic expression of PAX4 in endocrine precursors or even in $\alpha$-cells of transgenic mice is sufficient to force their conversion into $\beta$-cells, but not in $\delta$-cells [19]. These data demonstrate the essential role of PAX4 in $\beta$-cell differentiation. Surprisingly, while birds and amphibians possess pancreatic $\beta$ - and $\delta$-cells, no Pax4 gene has been reported in these organisms and examination of the chicken and Xenopus tropicalis genomic sequences indicates a lack of Pax4 ortholog in these two vertebrates.
A recent phylogenetic study strongly suggests that the Pax4 gene is derived from a duplication Pax6/eyeless gene which probably occurred at the so-called tworound (2R) genome duplication in early vertebrates [22]. This ancient Pax4 gene could have been lost in birds and some amphibians. In contrast, fish have the pax4 orthologous gene but its function in pancreatic cell differentiation is still unknown.

The lack of Pax4 gene in chick and Xenopus tropicalis is quite puzzling and raises the question about the pancreatic function of PAX4 protein during early vertebrate evolution and notably in fish. Two hypotheses can be proposed: i) PAX4 was important for $\beta$-and/or $\delta$-cell differentiation in the first vertebrate organisms but the loss of Pax4 gene in birds and amphibians has been compensated by another transcription factor or by others mechanisms, ii) the role of PAX4 in $\beta$ - and $\delta$-cell differentiation appeared later in vertebrate evolution. To tackle this question, we examined in the present study the expression and function of pax4 in zebrafish and investigated the regulatory links with the arx zebrafish orthologous gene. We show that pax4 is dispensable in zebrafish for the differentiation of the $\beta$-cells deriving from the dorsal bud, but has a role in the reduction of $\alpha$-cells. This role is mediated by repression of arx gene whose essential function in $\alpha$-cell formation appears to be maintained between zebrafish and mammals. In addition, our data uncover a so far unappreciated autorepression of pax4 and arx genes. We also analyzed the fate of endocrine cells after pax4 or arx knock-down. In light of our data, we propose a model where the main role of Pax4 during the initial phases of vertebrate evolution was to modulate the number of endocrine $\alpha$-cells.

\section{Results}

1) Expression of zebrafish arx and pax4 genes during pancreatic development.

The zebrafish pax4 gene sequence was identified on chromosome 4 by using the TBLAST program and the corresponding pax4 cDNA was amplified by RTPCR and 3'-RACE. Sequence comparison of the deduced zebrafish Pax4 protein with the human and mouse PAX4 proteins shows that the homeodomain and the paired domain are well conserved while the C-terminal domain is highly divergent (see Additional 1: Figure S1). As the neighbouring genes located to the 5' side from pax4 gene are the same in zebrafish, in mouse and in human (snd1 gene: staphylococcal nuclease domain containing 1; and lrrc4 gene: leucine rich repeat containing 4), this indicates that the zebrafish pax4 gene is the actual ortholog of the mammalian PAX4 genes (see Additional file 2: Figure S2). The zebrafish proteins 
showing the closest similarity with the deduced Pax4 zebrafish protein are Pax6a and Pax6b. Sequence comparison of vertebrates PAX4 and PAX6 proteins indicate that 13 amino acid positions are identical among the vertebrate PAX4 proteins while distinct from the PAX6 proteins (see Additional file 1: Figure S1). All together, these data indicate that, while the sequence of PAX4 genes were much less conserved during vertebrates evolution compared to the PAX6 genes, these $P A X 4$ genes are actual PAX4 orthologs.

The expression of zebrafish pax4 was analyzed by whole-mount in situ hybridization (WISH) at various stages of development. As described for the murine Pax4 gene, zebrafish pax4 transcripts were detected only in the pancreatic region, the first pax4+ cells appearing at the level of the dorsal pancreatic bud at around 16 hours post fertilization (hpf) (Figure 1A and B). pax4 pancreatic expression reaches its maximal level around 22-24 hpf, then progressively decreases and becomes hardly detectable after $40 \mathrm{hpf}$ (Figure 1C-F). Some pax4+ cells can occasionally be detected at larval stages (after $72 \mathrm{hpf}$ ) near the intrapancreatic ducts (data not shown).
While Miura and collaborators have previously detected arx transcripts in the telencephalon, diencephalon, floor plate and somites of zebrafish embryos, they did not report arx expression in the pancreas [23]. However, our WISH using the arx probe revealed expression in the pancreatic dorsal bud from $22 \mathrm{hpf}$ onward (Figure 1G-L). At $30 \mathrm{hpf}$, pancreatic arx staining displays the shape of a ring which is reminiscent of the disposition of glucagonexpressing $\alpha$-cells (Figure $1 \mathrm{~L}$ ). The levels of arx gene expression decreases at later developmental stages but its expression can still be detected in pancreas of larvae and adult zebrafish (data not shown). Another gene related to arx was found in the zebrafish genome; this novel arx-like gene (named ENSDARG00000075896.2 in Ensembl website) is expressed in the CNS but not in the pancreas (data not shown).

In order to identify the pancreatic cell types expressing arx and pax4, fluorescent in situ hybridizations were performed with various pancreatic markers between $16 \mathrm{hpf}$ and $30 \mathrm{hpf}$ (Figure 2). arx transcripts were detected in all glucagon+ cells and in some ghrelin+ cells, but not in

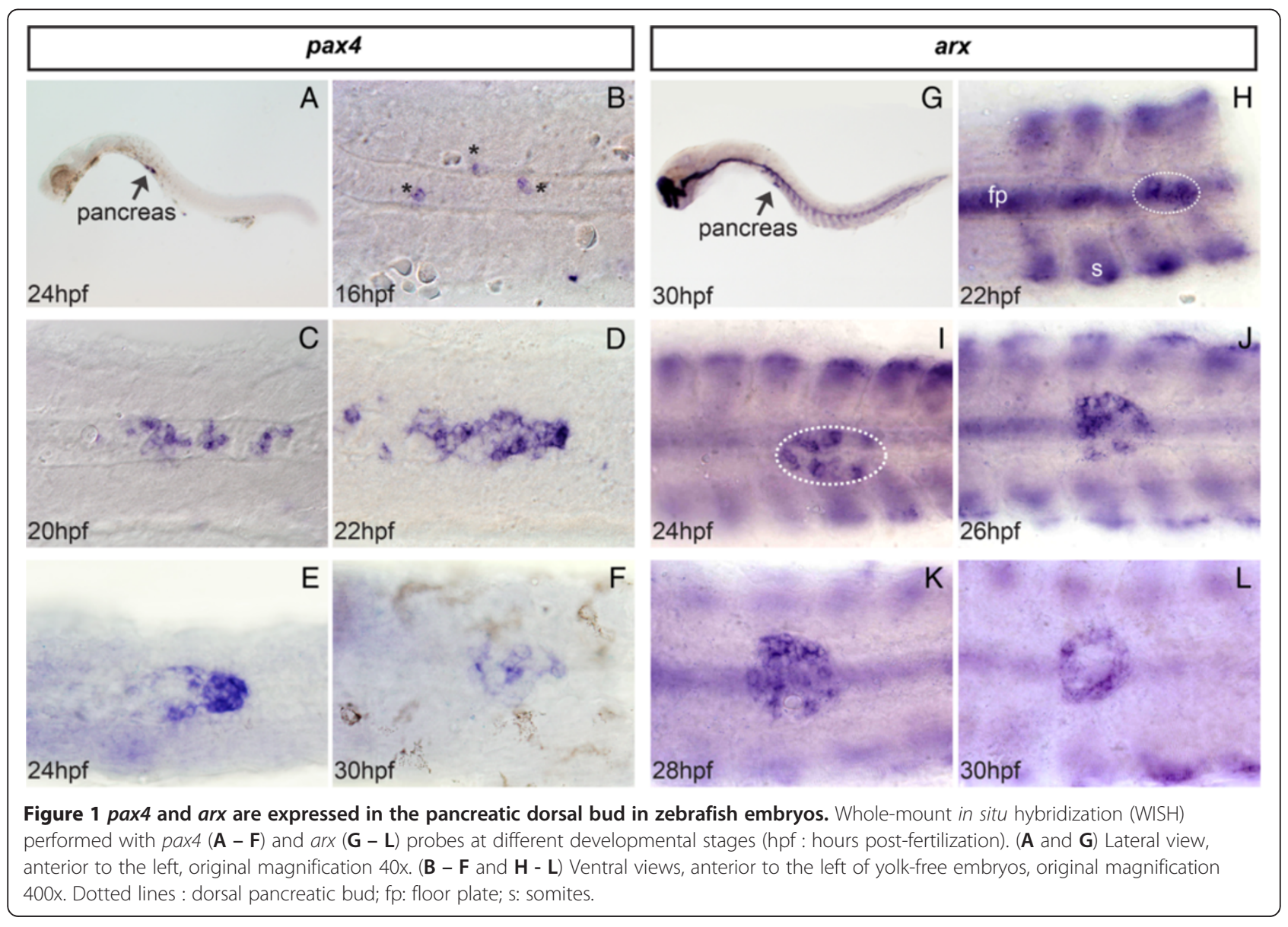




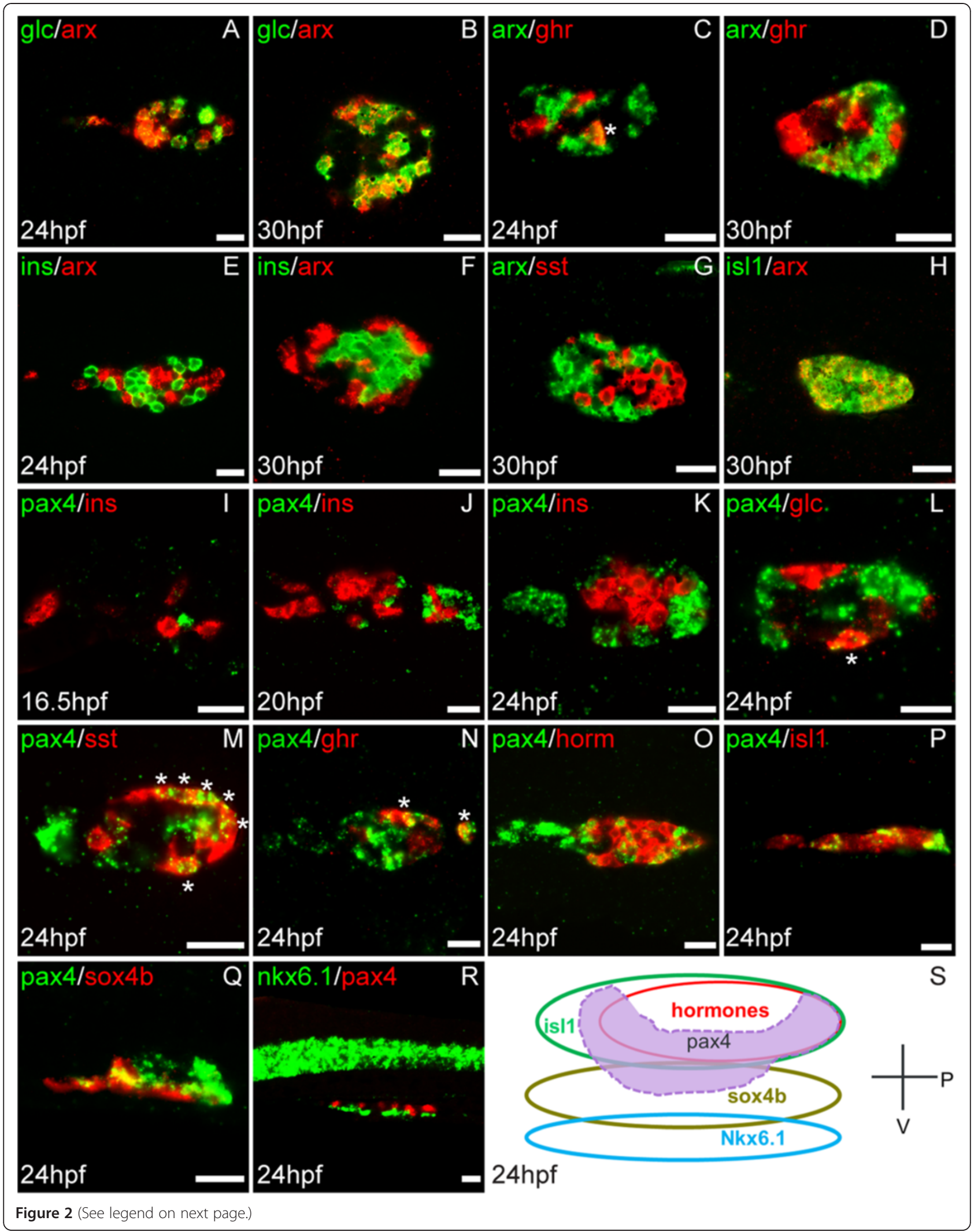


(See figure on previous page.)

Figure 2 Identification of pax4 and arx expressing cells by double fluorescent in situ hybridization. All images are confocal optical sections of the dorsal pancreatic bud with anterior part to the left. The probes and the developmental stages are respectively indicated at the top and the bottom in each image. All views are ventral, except images $\mathbf{P}, \mathbf{Q}, \mathbf{R}$ and $\mathbf{S}$ which are lateral views. arx transcripts are detected in almost all glucagon+ (A, B), in some ghrelin+ $(\mathbf{C}, \mathbf{D})$ cells and in many is/1+ cells $(\mathbf{H})$; absence of co-staining between arx and insulin $(\mathbf{E}, \mathbf{F})$ and somatostatin (G). pax4 transcripts are not detected in insulin+ $(\mathbf{I}-\mathbf{K})$ and most glucagon+ cells (L). pax4 is expressed in many somatostatin (M) and a few ghrelin (N) expressing cells. Partial co-staining of pax4 probe with a cocktail of insulin, glucagon, somatostatin and ghrelin probes (horm) $(\mathbf{O})$, with is/1 (P) and sox4b (Q) probes. Absence of co-staining between pax4 and $n k \times 6.1$ (R). S: Schematic representation of the multi-layer organization of the pancreatic dorsal bud at $24 \mathrm{hpf}$ including pax4 expression. Scale bar $=20 \mu \mathrm{m}$. astérisks $\left(^{*}\right)$ indicate double positive cells.

insulin + cells and not in somatostatin+ cells (Figure 2A-H). At $30 \mathrm{hpf}$, all arx + cells correspond to a subset of pancreatic post-mitotic isl1+ endocrine cells (Figure $2 \mathrm{H}$ ). Thus, the expression profile of arx is quite similar in zebrafish and mouse, being mainly restricted to $\alpha$-cells. In contrast, the pancreatic expression of pax4 seems different in mouse and zebrafish. Indeed, while Pax4 was detected in numerous differentiating $\beta$-cells in mouse embryos, we never observed co-localization of pax4 and insulin transcripts in zebrafish embryos and larvae (Figure 2I-K). Most $\alpha$-cells do not express pax4 (Figure 2L), although some cells coexpressing glucagon and pax4 could occasionally be found. In contrast, pax4 was detected in many somatostatin+ cells (in about $40 \%$ of $\delta$-cells) and ghrelin+ cells (about $15 \%$ of $\varepsilon$-cells) (Figure $2 \mathrm{M}$ and $\mathrm{N}$ ). In order to determine whether pax4 expression is restricted to hormone expressing cells, we performed a double staining of pax4 with a cocktail of the four hormone probes (Figure 1O). At $24 \mathrm{hpf}$, about half of the pax4+ cells were not labelled by the hormones. Isl1 being expressed in all post-mitotic endocrine cells, we also analyzed the expression of pax4 with this transcription factor. While many pax4+ cells were isl1+, some cells were found to be labelled only by the pax4 probe (Figure 2P). To determine whether pax4 is expressed in endocrine precursors, we next compared its expression with sox $4 b$, a marker of these precursors in zebrafish [24,25]. Many sox4+ cells were found to express pax4 (Figure 2Q). Finally, pax4 was not detected in pancreatic nkx6.1+ progenitors which are located ventrally to the developing islet (Figure 2R) [24]. Taken together, these data indicate that pax4 expression is restricted to pancreatic endocrine precursors and transiently in some differentiating endocrine cells such as $\delta$ - and $\varepsilon$-cells (see schematic diagram Figure 2S).

We next investigated whether pax4 and arx can be expressed in the same pancreatic cells. At $22 \mathrm{hpf}$, a substantial number of cells were found to contains both transcripts (Figure 3A-C); however, arx and pax4 expression progressively segregates into distinct cells afterwards and only 1 or 2 cells per islet positive for the two transcripts were observed at $30 \mathrm{hpf}$ (Figure 3D-I).

2) Function of $a r x$ and pax4 in zebrafish pancreatic cell differentiation.

To determine the function of the zebrafish pax4 and $a r x$ genes in pancreatic cell differentiation, we injected antisense morpholinos designed to target exon-intron junctions in both pre-mRNA and to alter the splicing of these transcripts. To determine the efficiency of these knock-down, mRNA was extracted from these injected zebrafish embryos (named morphants) and from control embryos, and we analyzed the pax4 and arx transcripts by RTPCR (see Additional file 3: Figure S3). The morpholino Mo1pax4 targeting the exon2-intron2 boundary was highly efficient as injection of $6 \mathrm{ng}$ was sufficient to block the removal of intron2 in almost all pax4 transcripts, while Mo2pax4 targeting exon1-intron1 junction was less efficient and partially inactivate the splicing at that site. Thus, Molpax4 was used for the subsequent functional studies. Similarly, 2ng of Moarx morpholino was sufficient to block the splicing of intron2 for almost all arx transcripts (see Additional 3: Figure S3). Analysis of arx morphants revealed a complete loss of $\alpha$-cells while the number of the other endocrine cell types was not significantly modified (Figure 4A-L). Injection of an unrelated morpholino (Mocont) or of the arx morpholino containing 5 mismatches in the exon2intron2 junction site did not cause any changes in the number of pancreatic cells. In contrast to arx knock-down, injection of Molpax4 did not decrease the number of any pancreatic endocrine cell types (Figure 5); instead, a small but highly reproducible increase in glucagon+ cells number was observed (Figure 5G-I; p 0.0001 ) as well as a very slight increase in ghrelin+ cells (Figure 5J-L; $\mathrm{p}<0.003)$. Consistent with the increased number of $\alpha$-cells, an increase in arx+ cells was also detected (Figure 5M-N) $(28 \pm 4$ and $41 \pm 5$, respectively; $\mathrm{n}=30$ ). Altogether, these data indicate that arx is required for $\alpha$-cell formation, as described in mouse; however, pax4 is not required for the 


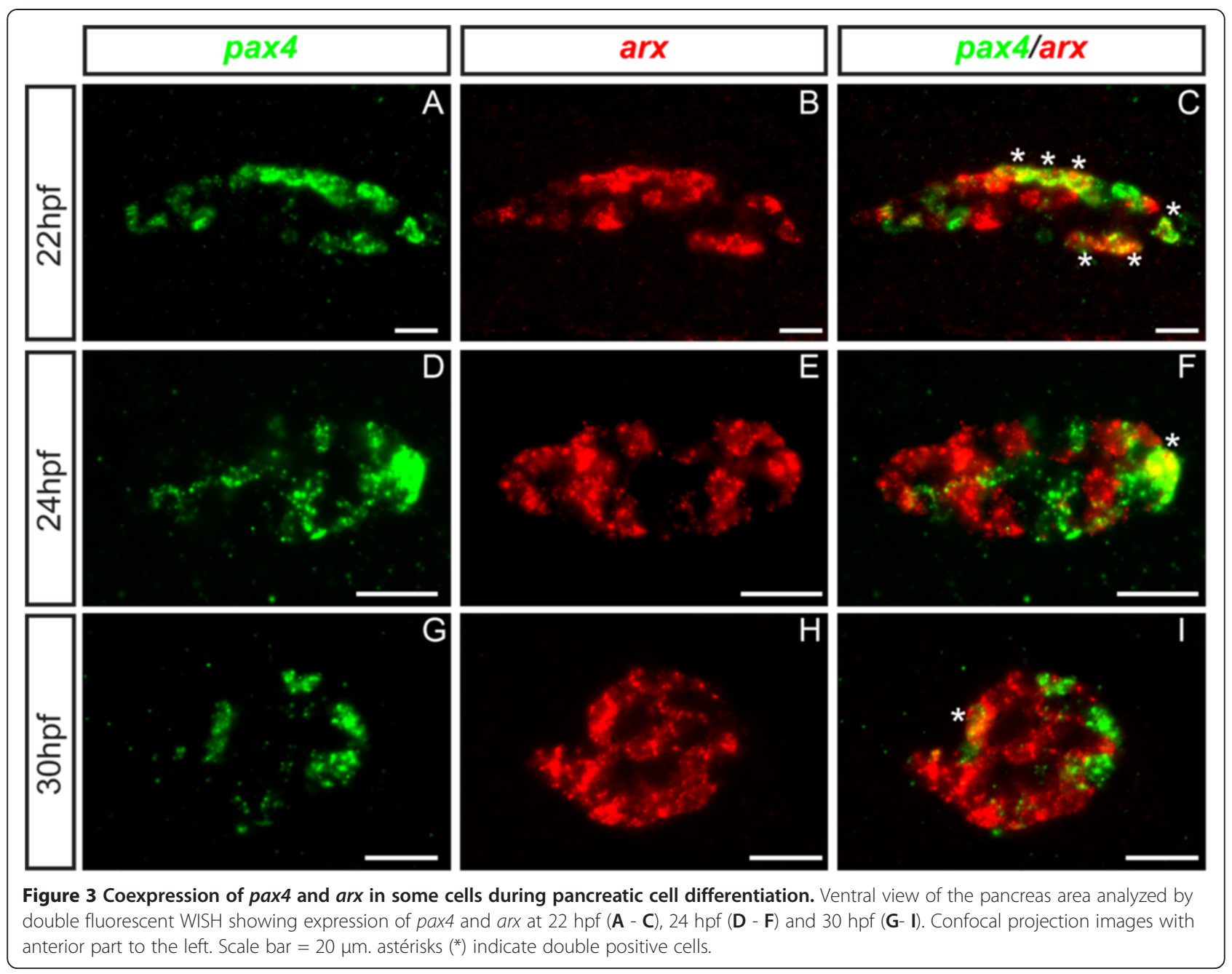

generation of the first $\beta$-cells of zebrafish embryos but appears to modulate $\alpha$-cell number.

3) Arx and Pax4 negatively autoregulate their own gene transcription.

To determine whether transcription of the arx and pax4 genes was affected after the inactivation of these two transcription factors, we next analyzed arx and pax4 transcript levels by WISH in arx and pax4 morphants, respectively (Figure 6). Surprisingly, while pax4 mRNA was mainly cytoplasmic in control embryos as expected, the altered pax4 transcripts were located in cell nuclei in Molpax4 morphants as revealed by colocalization with the nuclear marker TOPRO3 (Figure 6A-D). The intensity of fluorescence in nuclei was also higher in pax4 morphants and the number of pax4-labelled cells was significantly increased. Similar data were obtained using the second Mo2pax4 morpholino, albeit with slightly less pronounced effects (data not shown). These data suggested that splicing alteration disrupted the transport of pax4 transcripts from the nucleus to the cytoplasm and that a negative autoregulatory loop exists in the regulation of zebrafish pax4 gene.

Interestingly, a similar phenomenon was observed for the arx gene. Indeed, while the level of arx staining was low and cytoplasmic in control embryos, it became nuclear and very strong in arx morphants (compare Figure 6E and $\mathrm{F}$ for fluorescent WISH; compare Figure 6I and J for visible WISH). This up-regulation was observed in all tissues expressing arx gene such as the floor plate, brain, spinal cord and somites, but not in the pancreas. Indeed, while about 20 pancreatic cells are labelled by $a r x$ probe in control embryos, very low staining was observed in a maximum of 5 pancreatic cells in arx morphants. To determine if the retention of arx transcripts in nuclei and the stronger staining in most tissues were caused by splicing alteration induced by the morpholino, we injected another morpholino (MoTarx) targeting the translation start site of arx mRNA. This morpholino did not cause a 


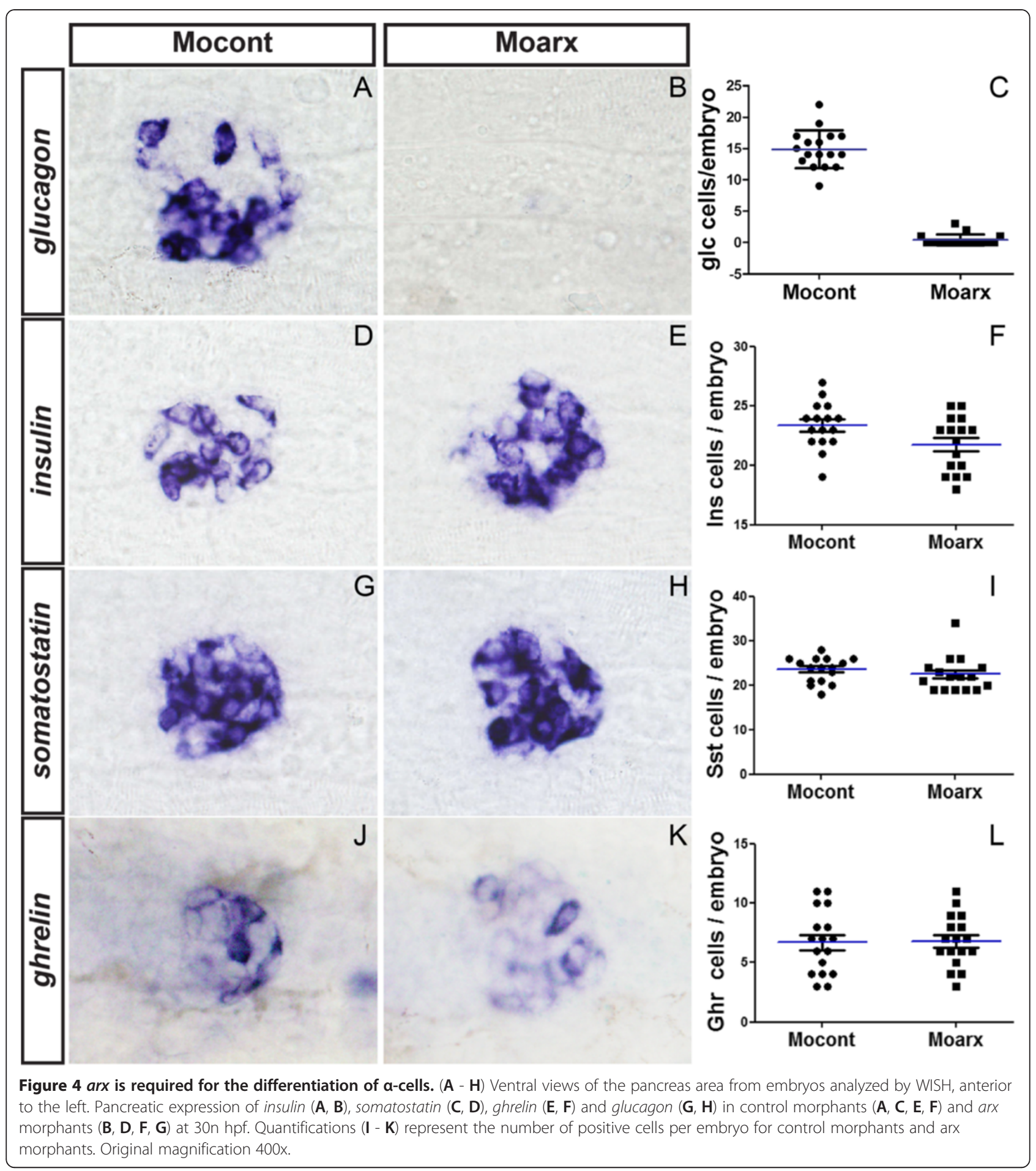

nuclear retention of arx transcripts, but it produced a strong increase in the level of arx transcripts in all tissues (compare Figure $6 \mathrm{~K}$ and $\mathrm{L}$ ), with the exception of pancreas where arx + cells could hardly be detected (Compare Figure 6M and $\mathrm{O}$, and see Additional 4: Figure S4 C,D). All together, these data indicate that i) splicing disruption is the cause of nuclear localization of transcripts and ii) a negative feed-back loop exists for Arx in all tissues, but is not detected in pancreas.

To verify that the up-regulation of arx transcripts in arx morphants is actually due to an auto-regulatory effect occurring at the level of arx gene transcription, we next used a zebrafish transgenic line in which 


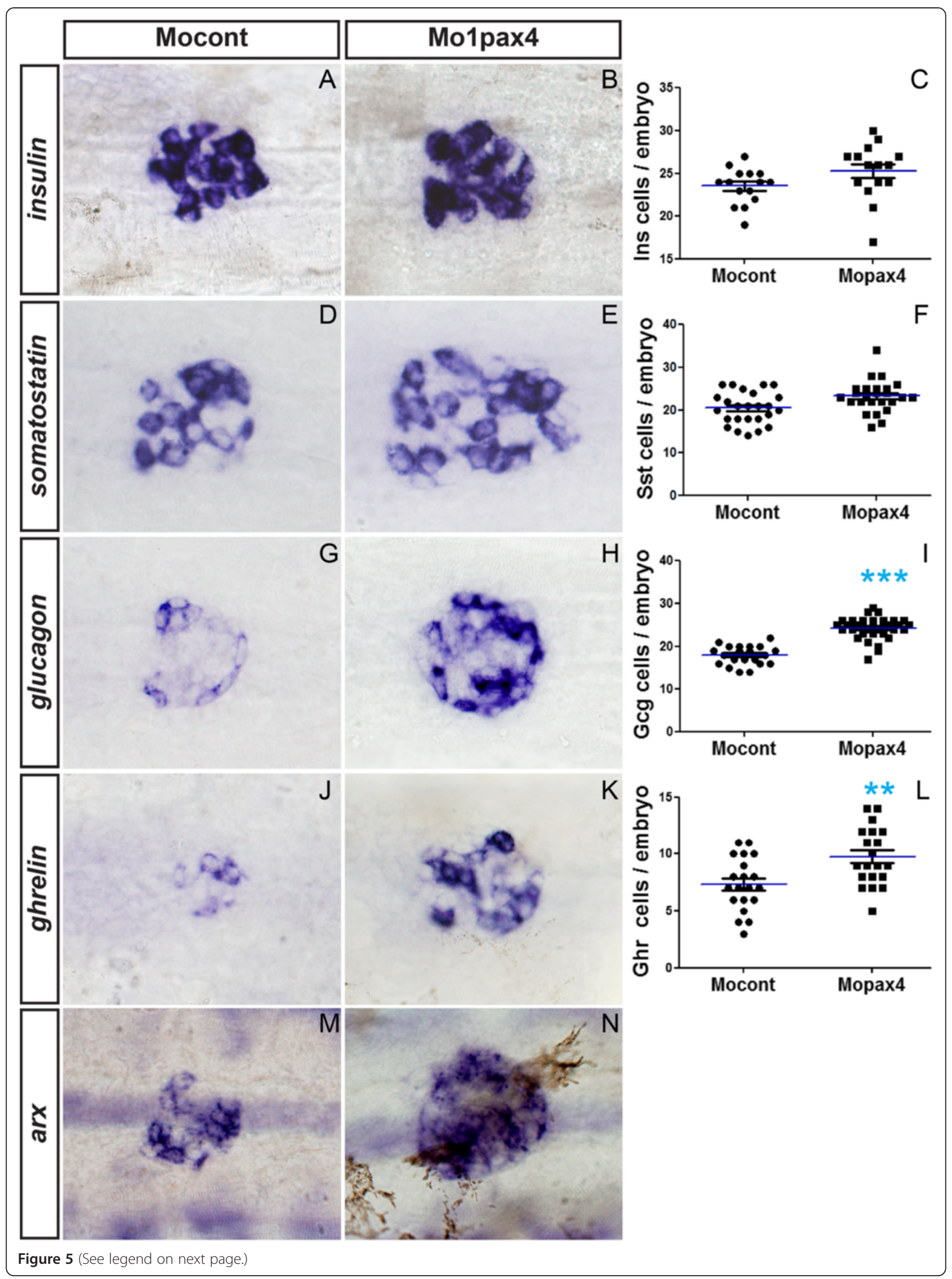


(See figure on previous page.)

Figure 5 Pax4 is not required for $\boldsymbol{\beta}$-cell differentiation. (A - J) Ventral views of the pancreas area from embryos analyzed by WISH, anterior to the left. Pancreatic expression of insulin $(\mathbf{A}, \mathbf{B})$, somatostatin $(\mathbf{C}, \mathbf{D})$, ghrelin $(\mathbf{E}, \mathbf{F})$, glucagon $(\mathbf{G}, \mathbf{H})$ and $\operatorname{arx}(\mathbf{I}, \mathbf{J})$ in control morphants $(\mathbf{A}, \mathbf{C}, \mathbf{E}, \mathbf{F}, \mathbf{I})$ and pax4 morphants (B, D, F, G, J) at 30 hpf. Quantifications ( $\mathbf{K}, \mathbf{L}, \mathbf{M}, \mathbf{N}$ ) represent the number of positive cells per embryo for control morphants and pax4 morphants. Asterisks (*) indicate that the difference between cell number in control morphants and pax4 morphants is statistically significant by Student's $t$-test $\left(* *: P<0.003 ;{ }^{* * *}: P<0.0001\right)$. Original magnification 400x.

GFP expression was driven by an enhancer of the human $A R X$ gene. Performing a systematic enhancer-screening assay [26], a sequence was identified that regulated GFP in the central nervous system identical to the endogenous zebrafish arx gene (Ishibashi et al. manuscript in preparation). When the arx morpholinos were injected in one of the transgenic lines, a significant up-regulation of GFP was observed compared to control embryos (Additional 5: Figure S5). This confirms the existence of an inhibitory action of Arx protein on the expression of its own gene, this auto-regulation being either direct or indirect.

4) Antagonistic actions of zebrafish Arx and Pax4 in pancreatic cell differentiation.

The increase of arx transcripts in the somites and the central nervous system of arx morphants contrasts with the clear down-regulation of arx transcripts in pancreatic cells. This suggests the involvement of a pancreas-specific factor thwarting or impeding the negative feed-back loop. As Pax4 is described as a repressor of the Arx gene in mouse and is selectively expressed in pancreas, this prompted us to verify whether the down-regulation of arx transcripts in pancreatic cells of arx morphants was due to Pax4 action. To that end, we compared the expression of arx transcripts in the arx morphants and in the double arx;pax 4 morphants. We found that indeed, that the levels of the pancreatic arx transcripts were much higher in the double morphants (Figure 6, compare M, O and P). These data demonstrate that zebrafish Pax4 represses arx gene expression in zebrafish and is the factor thwarting the arx negative feed-back loop in the pancreas. To further analyse the antagonistic actions of Arx and Pax4, we determined the pancreatic expression of these two genes by fluorescent WISH in the single and double arx;pax4 morphants at $30 \mathrm{hpf}$ (Figure 7). In control embryos, arx and pax4 transcripts were mostly detected in distinct cells at this stage. Following pax4 knockdown, we detected an up-regulation of both arx and pax4 transcripts and the nuclei of many arx + cells were also co-labeled by the altered pax4 transcripts (Figure 7B,F and J). In arx morphants, besides downregulation of $a r x$ gene transcription, increased number of pax4+ cells was noticed, with some of them expressing low amount of altered arx transcripts (Figure 7C,G,K). This co-expression was more obvious in the embryos injected with both arx and pax4 morpholinos, as the two altered transcripts were strongly detected in many nuclei and around $50 \%$ of $a r x+$ or pax $4+$ cells were co-labeled by the two probes (Figure 7D,H,L). In conclusion, as arx and pax4 are expressed in distinct cells in control embryos while the two genes are co-transcribed in many cells in the double morphants, this confirms the mutual repression of these two factors on the each gene.

5) Characterization of Arx- and Pax4-deficient cells in zebrafish morphants.

Our observation of the altered arx and paxy transcripts in the nucleus of pancreatic cells after their knock-down allows us to characterize these arx + and pax4+ cells and thereby we determined whether their identity is modified after their respective knock-down. As already mentioned above, in wild-type embryos at $30 \mathrm{hpf}$, pax4 is expressed in sox $4 b+$ endocrine precursors, in some $\delta$ - and $\varepsilon$-cells and is excluded from $\alpha$ cells (see Figure 2 and Figure 8). In the pax4 morphants, the expression profile of the altered pax4 transcripts remained essentially the same as in wild-type except that they were also detected in the nuclei of $\alpha$-cells (Figure 8A-H). These data suggest that, in the absence of functional Pax4 activity, the endocrine progenitors that should have expressed pax4 can give rise to $\alpha$-cells as well as to $\delta$ - and $\varepsilon$-cells. As arx gene transcription is strongly inhibited following arx knock-down, it was difficult to evaluate the identity of $a r x+$ cells in arx morphants using the same strategy. To circumvent this problem, we analyzed instead the identity of arx+ cells in the double arx; pax4 morphants where arx transcripts are easily detected. Like in the control embryos, arx transcripts were not detected in $\beta$ - or $\delta$-cells in the double morphants (Figure 8I,J,M and N). No glucagon expression could be detected confirming the efficiency of $a r x$ knock-down. Only a minority of arx + cells expressed ghrelin, while the majority was not stained by any other of the hormone probes (Figure 8I-P). These data indicate that the fate of 


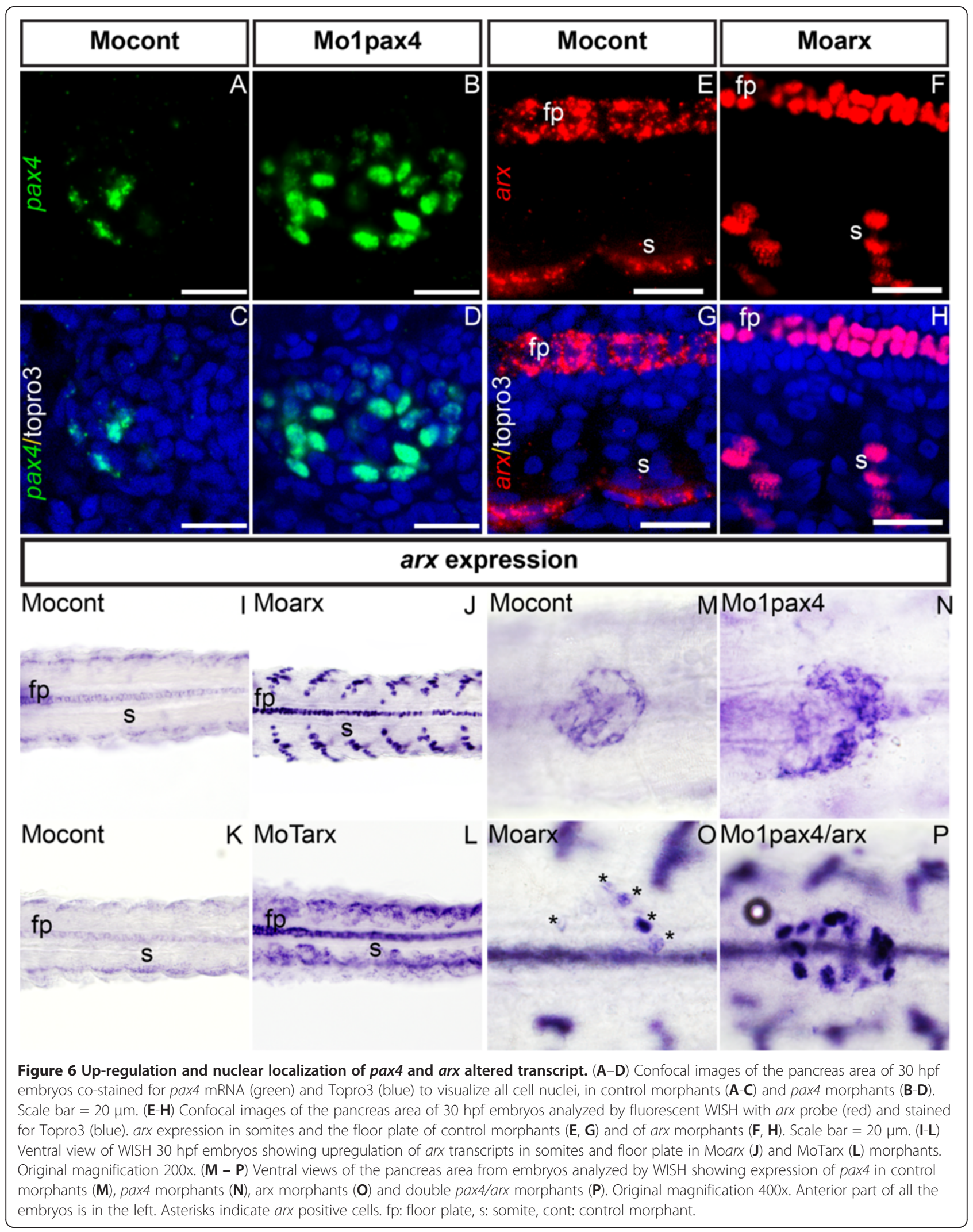




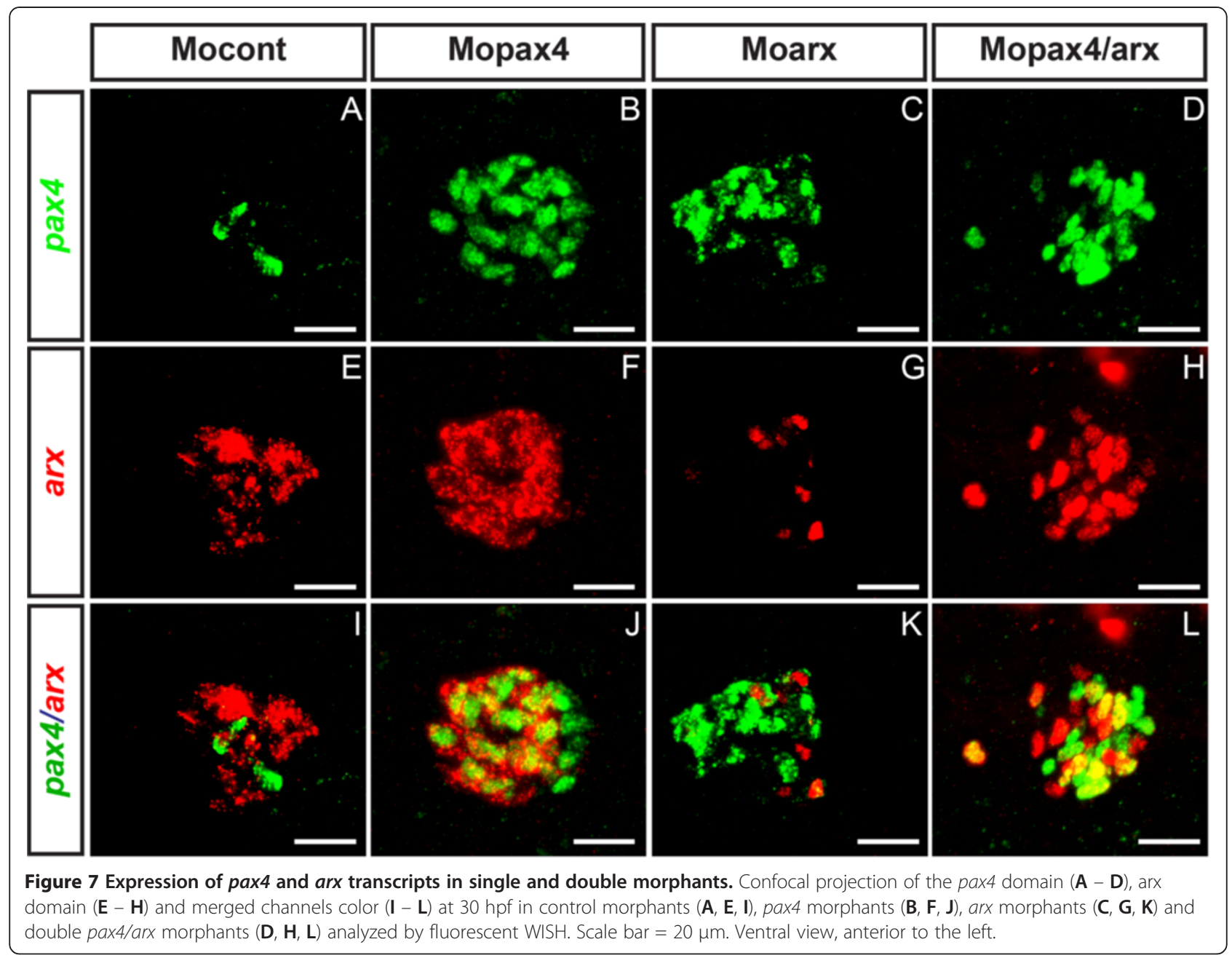

arx + cells has not been switched to another cell type after arx;pax4 knock-down and that these arx + cells are probably blocked in their differentiation process toward $\alpha$ cells.

\section{Discussion}

Previous studies in mouse have shown that the balance of $\alpha$-cells versus $\beta / \delta$-cells is controlled by the antagonistic action of ARX and PAX4 homeodomain factors, ARX being required for $\alpha$-cell identity and, inversely, PAX4 favoring $\beta$ - and $\delta$-cell fate at the expense of $\alpha$-cells (see Figure 9) [27]. PAX4 is also sufficient in mice to convert $\alpha$-cells to $\beta$-cells [19]. However, the lack of PAX4 gene in birds and in some amphibians, which possess $\beta$-cells, raises the question of its original function in lower vertebrates such as fish. In this study, we show that pax4 is not required for $\beta$ - and $\delta$-cell differentiation in zebrafish embryos but modulates the number of $\alpha$-cells through repression of the arx gene (Figure 9). Zebrafish Arx is required for $\alpha$-cell differentiation and has a repressive action on pax4 gene expression, like in mouse. Thus, we can reasonably conclude that the mutual repression between Pax4 and Arx was established early in vertebrate evolution and that pax4 was not required for $\beta$-cell differentiation in the first vertebrate species such as fish; the crucial role of Pax4 in $\beta$-cell differentiation could have appeared much later, possibly during mammals' evolution.

Comparison of the peptidic sequence of zebrafish Pax4 with its human and murine orthologs reveals strong divergence beside the homeodomain and the paired domain. In contrast, the sequence of the closely related Pax6 proteins has been extremely conserved. Nevertheless, several observations indicate that the zebrafish Pax4 protein is the actual ortholog of the mammalian Pax4; indeed, i) 13 amino acid residues of the homeodomain and paired domain are common between the Pax4 proteins of different species while divergent in Pax6 proteins, ii) synteny is clearly identified between the vertebrate Pax4 genes, iii) the zebrafish pax4 gene, like mouse Pax4, is specifically expressed in pancreatic endocrine precursors and not in other tissues, and iv) we 


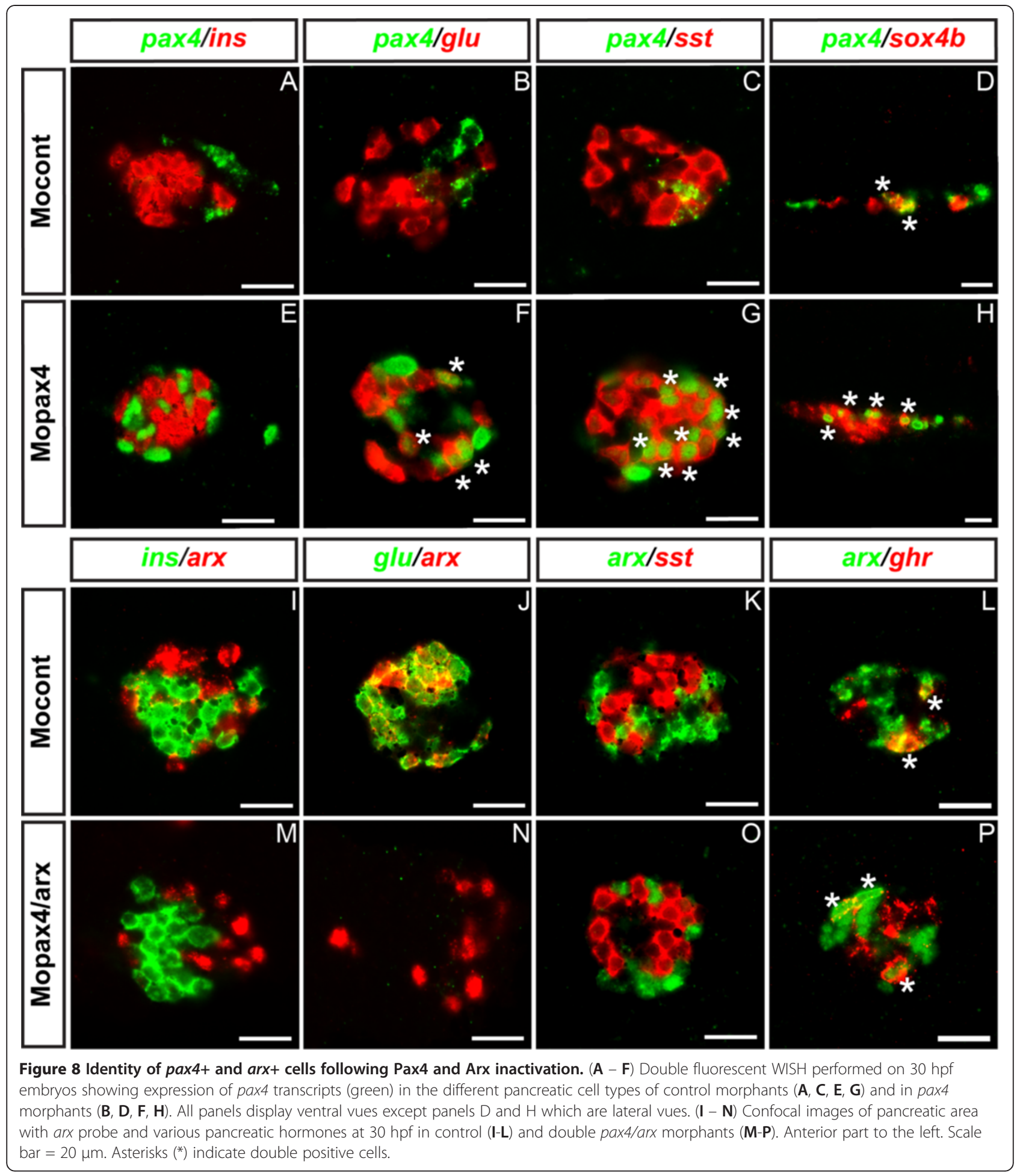

observe an antagonism between the zebrafish pax4 and arx genes as reported in mouse. Surprisingly, we could not detect any expression of zebrafish pax4 in differentiating $\beta$-cells in the embryos as well as in the $5 \mathrm{dpf}$ larvae (data not shown). As a second pax4 paralog could not be identified in the zebrafish genome and as the efficiency of our pax4 knock-down experiment was high, we can conclude that pax4 is clearly not essential for the generation of $\beta$-cells in zebrafish embryos. In contrast to pax4, the pancreatic expression and function of arx gene seems to have been well maintained throughout vertebrate evolution. Indeed, this gene is expressed in all $\alpha$ - 


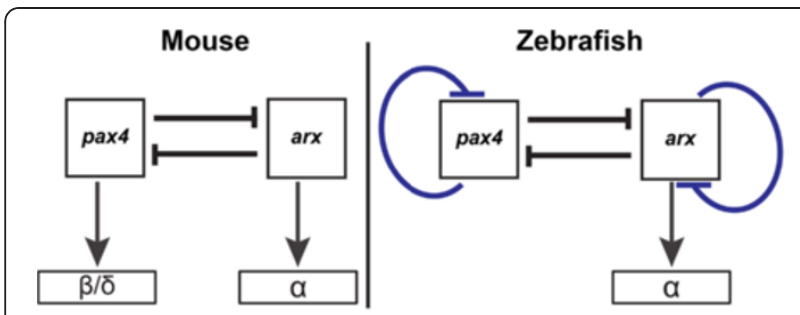

Figure 9 Comparison of the pax4 and arx regulatory circuits in zebrafish and mouse. A mutual repression between arx and pax4 is present in both species and a-cell differentiation relies on Arx activity. While PAX4 is required for $\beta$ - and $\delta$-cell formation in mouse, it is dispensable in zebrafish for that function. In zebrafish, Arx and Pax4 can repress their own expression. All interactions can be either direct or indirect.

cells and is required for their differentiation as in mouse. As the analyses of arx and pax4 morphants were performed in this study at $30 \mathrm{hpf}$, the function of arx and pax4 genes was tested only for the pancreatic endocrine cells deriving from the dorsal pancreatic bud. Do the Arx and Pax4 factors have the same role in the second wave of endocrine cells appearing in the zebrafish larvae after $3 \mathrm{dpf}$ and which derive from the ventral pancreatic bud? While our unpublished data show the absence of glucagon in a minority of arx morphants and the presence of secondary insulin cells in some pax4 morphants at $5 \mathrm{dp}$, it is difficult to draw clear-cut conclusions as the knock-down efficiency decreases in the zebrafish larvae 4 days after morpholinos injection. Late function of arx and paxy genes will require the generation and analysis of arx and pax4 mutants.

An interesting point raised by the present study is the observation that altering the splicing of a particular RNA causes its retention in the nucleus. Retention of incorrectly spliced transcript has been previously described in yeast and seems to be part of a quality control mechanism set up in eukaryotes to prevent the synthesis of truncated and potentially deleterious proteins [28,29]. The nuclear location of altered pax4 and arx transcripts allowed us to characterize the pax4- and arx-deficient cells in morphants. Using this strategy, we could highlight that the cells expressing the altered pax4 transcripts correspond to endocrine precursors, $\varepsilon$ - and $\delta$-cells like in control embryos, but also to $\alpha$-cells in pax4 morphants. pax4 transcripts could not be detected in $\beta$-cells either in control embryos or in pax4 morphants. This is in sharp contrast with data obtained in mouse and reinforces our conclusion that, in zebrafish, pax4 is not involved in $\beta$-cell differentiation. arx was expressed in all $\alpha$-cells and in some $\varepsilon$-cells in control embryos. Analysis of the double arx/pax4 morphants revealed no change in the fate of the $a r x+$ cells and rather indicated a blockage in their differentiation process towards $\alpha$-cells. Such data are also contrasting with those reported in mouse where the pancreatic cells switch from $\alpha$-cell toward $\beta$ - or $\delta$ cell fate in the Arx KO mice [12]. The reason for such a difference is unclear but a likely explanation could be again the lack of Pax4 function in $\beta / \delta$ fate decision in zebrafish. Indeed, if Pax 4 was sufficient to specify $\beta$-cell fate in zebrafish like in mouse, the increased number of pax4-expressing cells in arx morphants should have resulted in additional $\beta$-cells. The nuclear retention of unspliced transcript is an useful phenomenon allowing to i) to easily verify the efficiency of the knock-down induced by morpholinos in a single zebrafish morphant, and ii) to identify and characterize the cells that should normally have expressed the studied factor. The blockage of mRNA nuclear export seems to occur only if an entire intron remains within the mRNA. Indeed, in other cases, morpholinos targeting exon-intron junctions can also lead to the use of neighbouring cryptic splicing sites or to the removal of whole exon(s), as previously shown for pax6b or bmp $2 a[13,30]$. In these latter cases, we did not observe a nuclear retention of the altered transcripts (data not shown).

Our study also demonstrates a negative autoregulation of Arx and Pax4 on their own gene expression. Indeed, the knock-down of pax4 leads to an increase in the number of pancreatic cells expressing high level of altered pax4 transcripts. Similarly, arx knockdown causes a striking increase in the level of arx transcripts in all tissues expressing this gene, except in the pancreas. Direct negative auto-regulation is a common feature found in many organisms allowing repressors to rapidly reach a steady-state in their expression level and preventing an excess of their expression. However in the pancreas, the levels of arx transcripts were dramatically reduced following arx knock-down, indicating that the negative feed-back was thwarted or blocked by another regulatory circuit. We demonstrated that this is due to the repressive action of Pax4 whose expression level is up-regulated in arx morphants. The feed-back loop of Arx on its own gene was further verified on a transgene driving GFP expression under the control of ARX regulatory sequence. These data demonstrate that the regulation occurs at the gene transcription level; if this effect is direct or mediated by (a) factor(s) regulated by Arx protein, is still unknown.

It is noteworthy to mention that, while both pax4 and arx are negative regulators of each other and of their own gene, the transcription of these 2 genes is regulated in opposite ways after their respective knock-down: indeed, loss of Pax4 activity leads to an up-regulation of pax4 transcripts while loss of Arx activity causes a down-regulation of arx transcripts in pancreatic cells. How to explain such opposite behaviors as the actions of both factors seems identical on each gene (see Figure 9B)? One explanation could be the different 
timing of their onset. Indeed, as pax4 expression starts at $16 \mathrm{hpf}$ long before arx which appears around $22 \mathrm{hpf}$, the knock-down of pax4 leads to an increase of pax4 transcription that cannot be thwarted by Arx between 16 and $22 \mathrm{hpf}$. In contrast, the knock-down of Arx activity will directly enhance pax4 expression which will then represses arx gene expression. Interestingly, a negative autoregulation of human PAX4 gene has been previously reported through in vitro experiments [31]. Thus, it is likely that the auto-regulation we describe here for zebrafish arx and pax4 genes exists in many vertebrates such as humans.

\section{Conclusions}

Our study demonstrates that, on one hand, the role of Arx in $\alpha$-cell differentiation has been maintained from fish to mammals, but on the other hand, Pax4 has no apparent function in the formation of $\beta$-cell in zebrafish embryos. Thus, we propose that PAX4 acquired its essential role in $\beta$-cells differentiation quite late in vertebrates' evolution. This can explain why chicken or Xenopus generate $\beta$-cells although they do not possess any PAX4 gene. Transcription factors shown to be crucial for pancreatic cell differentiation in mammals generally display conserved pancreatic expression in lower vertebrates such as zebrafish, suggesting that the regulatory network controlling pancreatic cell differentiation is similar across vertebrate species. The present study shows that there are nevertheless some differences in the action of particular transcription factors, like PAX4. Another zebrafish transcription factor could play the same role as the mammalian PAX4. One possible candidate is the $\mathrm{Mnx} 1 / \mathrm{Hb} 9$ homeodomain protein which is required for $\beta$-cell differentiation in zebrafish [32] and has been recently shown to repress $\alpha$-cell fate [33], as described for PAX4 in mouse. Further experiments will be required to test this hypothesis.

\section{Methods}

\section{Zebrafish strain}

Zebrafish (Danio rerio) embryos and adults (AB strain) were raised and cared for according to standard protocols [34]. Wild-type embryos were used and staged according to Kimmel et al. [35]. Animal care and experimental use were approved by the Animal Ethical Committee of University of Liège (File \#1172).

\section{Cloning of the zebrafish pax4 gene}

The zebrafish pax4 gene was identified by performing a TBLAST search on the Ensembl Genome Browser site (www.Ensembl.org) using the mouse Pax4 protein sequence. pax4 cDNA was cloned by nested RT-PCR on mRNA extracted from $12 \mathrm{hpf}$ to $31 \mathrm{hpf}$ embryos using two different pairs of primers; the first pair corresponding to 5'-GGAGTGTAAATCAGCTGGGT GGTGTG (upstream primer) and 5'-GCTCCCTCCT CATCCTCGCTCTACG (downstream primer) and the second pair corresponding to 5'- CGGACGTCCTC TGCCTGTCTACAAGC (upstream primer) and 5'GGTCAGCAGATCTGGATAAAGCCCAC (downstream primer). Amplification was obtained with 30 cycles of $10 \mathrm{~s}$ at $94^{\circ} \mathrm{C}, 30 \mathrm{~s}$ at $64^{\circ} \mathrm{C}$ (outer primers) or $60^{\circ} \mathrm{C}$ (inner primers), and $60 \mathrm{~s}$ at $68^{\circ} \mathrm{C}$, followed by a final $7 \mathrm{~min}$ extension at $68^{\circ} \mathrm{C}$. The $541 \mathrm{pb}$ product was then cloned in pGEM $^{\circledR}$-T Easy vector (Promega), and sequenced.

The 3' end of the pax4 gene was completed by 3' RLMRACE according to the supplier protocol (FirstChoice ${ }^{\circledR}$ RLM-RACE Kit, Ambion) on mRNA extracted from 24 hpf embryos. Briefly, mRNA were reverse transcribed using as primers the provided poly-dT 3' RACE adapter oligonucleotide. The 3' pax4 cDNA sequences were amplified by performing a nested PCR using as 3 ' primers the outer and inner 3 ' adapters provided by the supplier and as $5^{\prime}$ primers the pax4 outer and inner primers (pax4 outer primer: 5'-GGCGACTGAGGGAATGAGACC; pax4 inner primer: 5'- CCTGTGGGCTTTATCCAGATCT). The amplified cDNA was cloned in $\mathrm{pCR}^{\circledR}$ II-TOPO ${ }^{\circledR}$ vector (Invitrogen), and sequenced. The deduced pax4 mRNA sequence was deposited to NCBI Genbank (FJ713024.1).

\section{Single and double fluorescent whole-mount in situ hybridization}

Single whole-mount in situ hybridizations were performed as previously described by Hauptmann and Gerster [36]. Anti-sense RNA probes were synthesized by transcription of cDNA clones with T7, T3 or SP6 RNA polymerase and using digoxigenin labelling mix (Roche) or DNP-11-UTP (TSA ${ }^{\mathrm{m}}$ Plus system, Perkin Elmer). They were subsequently purified on NucAway spin columns (Ambion) and ethanol precipitated. Double fluorescent in situ hybridizations were carried out as described by Mavropoulos et al. [25]. The pax4 probe was generated by linearization of the 3'-RACEpCRII-TOPO plasmid with $X b a \mathrm{I}$ and transcription with SP6 RNA polymerase. The following probes were also used: arx [23], nkx6.1 [37], neuroD [38], glucagon [39], insulin [40], somatostatin [39], ghrelin [41], sox4b [25], and isl1 [42]. The cocktail of four hormones probes namely glucagon, insulin, somatostatin and ghrelin were used to analyse global hormone expression.

Cell counting for visible whole mount in situ hybridization was performed directly under the microscope by focusing successively on each layer of stained cells.

\section{Imaging}

All visible whole mount in situ hybridization images were taken using a digital camera connected to BX60 
Olympus Microscope. The Analysis ${ }^{\circledR}$ program (Soft Imaging System GmbH, Belgium) was then used for image processing. Confocal imaging was performed with a Leica TCS SP2 inverted confocal laser microscope (Leica Microsystems, Germany). Pictures were processed using Adobe Photoshop software and adobe illustrator for figure mounting.

\section{Morpholino design and injections}

Anti-sense morpholino oligonucleotides were designed and purchased from Gene Tools (Philomath, OR). Knock-down of arx was achieved either by the morpholino Moarx targeting the intron 2 - exon 2 junction (5'-GCGTCATATTTACCTGGTGAACACA) or by the morpholino MoTarx blocking the translation (5'TCGTCGTCGTACTGACTGCTCATGT). Two splicing blocking morpholinos were used for pax4 knock-down: Molpax4 targeting exon 2 - intron 2 junction (5'TAGCCTACACTTGGCACTTGATCTC) and Mo2pax4 targeting exon 1 - intron 1 junction (5'-AGGTGAGA AGTTTACCTTCAGTATT). The amount of morpholinos injected in each embryo was 2ng for Moarx, 1ng for MoTarx, 6ng for Mo1pax4. Double knock-down experiments were performed by injecting simultaneously $5 \mathrm{ng}$ of Mo1pax4 and 2ng of Moarx. All the morpholinos were diluted in Danieau solution containing Rhodamine dextran $0.5 \%$ from which $1 \mathrm{~nL}$ was injected into the yolk of one-cell stage wild-type embryos. A standard control Morpholino (Mocont) that does not target any gene was also designed by Gene Tools and used as control (5'-CCTCT TACC TCAGTTACAATTTATA).

The confirmation of the arx negative autoregulation was performed by injecting the arx morpholinos and control morpholinos in a stable transgenic line $\operatorname{Tg}(\mathrm{ARX}$ enhancer:GFP)(Ishibashi et al. manuscript in preparation). Injected and non injected eggs were raised in E3 solution at $28^{\circ} \mathrm{C}$ and GFP expression was analyzed in the embryos at 2 and $3 \mathrm{dpf}$ using a Leica inverted fluorescent microscope. Settings for the microscope and camera software (Nikon) were kept constant for all images. Embryos were also imaged at $3 \mathrm{dpf}$ using a Zeiss LSM710 confocal and Zen software with constant settings (Laser intensity, pinhole, detector gain, scan speed, temperature and objective). Fluorescence was recorded as a square 16-bit image with edge length of 1024 pixels, and an average of 90 slices per embryos were generated. A minimum of ten embryos per condition were scanned. Each stack was projected into a $2 \mathrm{D}$ image using a maximum intensity projection in image $J$ software. Integrated fluorescent density was then evaluated for each projection in image $J$ and analyzed with excel. A $t$-test was used to compare obtained data.

\section{Additional files}

Additional file 1: Figure S1. PAX4 and PAX6 peptidic sequence alignment. The residues identical in all species are in yellow boxes, and the conserved residues in the majority of sequences are shaded in blue. The paired domain and the homeodomain are indicated by a line. The asterisks indicate amino acid positions conserved in all PAX4 sequences and different in PAX6 sequences, and hyphens indicate gaps in the peptidic sequence. Hs: Homo sapiens, Mm: Mus musculus, Dr: Danio rerio.

Additional file 2: Figure S2. Chromosomal locations of the zebrafish and human PAX4/PAX6 genes. Comparisons of the PAX4 locus as well as the PAX6 locus in zebrafish and human showing synteny. PAX4 genes are flanked by SND1 and LRRC4 genes in all examined vertebrates. FSCN3 and ARF5 genes are located downstream of PAX4 in human (and mammals) while hgfa and cacna2d1 genes are found downstream pax4 in zebrafish (and all examined fish species).

Additional file 3: Figure S3. Disruption of pax4 and arx RNA splicing by morpholinos. Schematic representation of pax 4 and arx pre-mRNA showing the exon-intron junctions recognized by Mo1pax4, Mo2pax4 and Moarx morpholinos. $P^{\prime}$ and $P^{\prime \prime}$ indicate the locations of primers used for RT-PCR analyses. Gels on left show the amplified CDNA from control and morphants revealing the presence of intronic sequences in pax4 RNA for morphants. No amplification could be obtained for arx RNA from arx morphants due to the insertion of the $1687 \mathrm{bp}$ intron 2.

Additional file 4: Figure S4. arx knock-down using the translation blocking morpholino MoTarx. Analysis by WISH of glucagon expression $(A, B)$ and of arx expression $(C, D)$ in control embryos $(A, C)$ and in embryos injected with MoTarx morpholino (MoTarx) (B,D). Ventral view, anterior to the left of pancreatic area at 400X magnification p: pancreas. Note the loss of pancreatic arx expression in MoTarx morphants and the cytoplasmic localisation of arx transcripts in both control and morphants.

Additional file 5: Figure S5. Expression of the Tg(ARX enhancer:GFP) transgene is increased by arx knock-down. Representative images of Tg (ARX_enhancer:GFP) transgenic embryos that have been injected with arx morpholino in comparison to uninjected embryos and embryos injected with a standard control morpholino. Fluorescent overview images were taken with an inverted microscope (A), while fluorescent intensities were measured by confocal microscopy (B) and quantified (C) as described in Materials and Method. A. Lateral view of $2 \mathrm{dpf}$ Tg(ARX_enhancer:GFP) embryos injected with ARX morpholino (2ng), control morpholino (2ng) or uninjected. B. Maximum intensity projection of confocal stack of $3 \mathrm{dpf}$ Tg(ARX_enhancer:GFP) embryos (dorsal view) injected with ARX morpholino (2ng), control morpholino (2ng) or uninjected. C. Fluorescent intensity measurements. Means of 10 embryos \pm Standard Deviation. Different from control at ${ }^{*} \mathrm{P}<0.001$.

\section{Competing interest}

The authors declare that they have no competing interests.

\section{Authors' contribution}

JD and $W$ performed the experiments and participated in the writing of the paper. EM, MI, JG and SR have performed data described in Additional file 5: Figure S5. IM, MV and BP supervised the work, analyzed the data and wrote the paper. All authors read and approved the final manuscript.

\section{Acknowledgments}

J.D. and V.V. were supported respectively by Télévie and FRIA grants. B.P. and M.L.V. are "Chercheurs qualifiés FNRS". I.M. was supported by the FNRS-FRS and by the "Action de Recherches Concertées" (University of Liège). This work was funded by the Belgian State's "Interuniversity Attraction Poles" Program (SSTC, PAI) and by the $6^{\text {th }}$ European Union Framework Program (BetaCellTherapy Integrated Project). M.I. and E.M. were supported by $7^{\text {th }}$ European Union Framework Program (NeuroXsys; FP7/2007-2013; grant 223262). SR is funded by the Medical Foundation of the University of Sydney. We thank Dr S. Ormenese from the "GIGA-Cell Imaging" facility, and Dr. M. Winandy from the "GIGA-Zebrafish Facility". 


\section{Author details}

${ }^{1}$ From Unit of Molecular Biology and Genetic Engineering, Giga-Research, University of Liège, 1 avenue de l'Hôpital B34, Sart-Tilman B-4000, Belgium. ${ }^{2}$ From Developmental Neurobiology and Genomics, Brain and Mind Research Institute, University of Sydney, Camperdown, NSW 2050, Australia.

Received: 4 April 2012 Accepted: 14 December 2012

Published: 17 December 2012

\section{References}

1. Edlund $\mathrm{H}$ : Pancreatic organogenesis-developmental mechanisms and implications for therapy. Nat Rev Genet 2002, 3(7):524-532.

2. Murtaugh LC: Pancreas and beta-cell development: from the actual to the possible. Development 2007, 134(3):427-438

3. Jensen J: Gene regulatory factors in pancreatic development. Dev Dyn 2004, 229(1):176-200.

4. Offield MF, Jetton TL, Labosky PA, Ray M, Stein RW, Magnuson MA, Hogan BL, Wright CV: PDX-1 is required for pancreatic outgrowth and differentiation of the rostral duodenum. Development 1996, 122(3):983-995.

5. Kawaguchi Y, Cooper B, Gannon M, Ray M, MacDonald RJ, Wright CV: The role of the transcriptional regulator Ptf1a in converting intestinal to pancreatic progenitors. Nat Genet 2002, 32(1):128-134

6. Jonsson J, Carlsson L, Edlund T, Edlund H: Insulin-promoter-factor 1 is required for pancreas development in mice. Nature 1994, 371(6498):606-609.

7. Naya FJ, Huang HP, Qiu Y, Mutoh H, DeMayo FJ, Leiter AB, Tsai MJ: Diabetes, defective pancreatic morphogenesis, and abnormal enteroendocrine differentiation in BETA2/neuroD-deficient mice. Genes Dev 1997, 11(18):2323-2334.

8. Gradwohl G, Dierich A, LeMeur M, Guillemot F: neurogenin3 is required for the development of the four endocrine cell lineages of the pancreas. Proc Natl Acad Sci USA 2000, 97(4):1607-1611.

9. Sussel L, Kalamaras J, Hartigan-O'Connor DJ, Meneses JJ, Pedersen RA, Rubenstein JL, German MS: Mice lacking the homeodomain transcription factor Nkx2.2 have diabetes due to arrested differentiation of pancreatic beta cells. Development 1998, 125(12):2213-2221.

10. Sosa-Pineda B, Chowdhury K, Torres M, Oliver G, Gruss P: The Pax4 gene is essential for differentiation of insulin-producing beta cells in the mammalian pancreas. Nature 1997, 386(6623):399-402.

11. Sander M, Sussel L, Conners J, Scheel D, Kalamaras J, Dela Cruz F, Schwitzgebel V, Hayes-Jordan A, German M: Homeobox gene Nkx6.1 lies downstream of Nkx2.2 in the major pathway of beta-cell formation in the pancreas. Development 2000, 127(24):5533-5540

12. Collombat P, Mansouri A, Hecksher-Sorensen J, Serup P, Krull J, Gradwohl G, Gruss P: Opposing actions of Arx and Pax4 in endocrine pancreas development. Genes Dev 2003, 17(20):2591-2603.

13. Verbruggen $V$, Ek $O$, Georlette D, Delporte F, Von Berg V, Detry N, Biemar F, Coutinho P, Martial JA, Voz ML, et al: The Pax6b homeodomain is dispensable for pancreatic endocrine cell differentiation in zebrafish. J Biol Chem 2010, 285(18):13863-13873.

14. Heller RS, Stoffers DA, Liu A, Schedl A, Crenshaw EB 3rd, Madsen OD, Serup P: The role of Brn4/Pou3f4 and Pax6 in forming the pancreatic glucagon cell identity. Dev Biol 2004, 268(1):123-134.

15. Wang J, Elghazi L, Parker SE, Kizilocak H, Asano M, Sussel L, Sosa-Pineda B: The concerted activities of Pax4 and Nkx2.2 are essential to initiate pancreatic beta-cell differentiation. Dev Biol 2004, 266(1):178-189.

16. Greenwood AL, Li S, Jones K, Melton DA: Notch signaling reveals developmental plasticity of Pax4(+) pancreatic endocrine progenitors and shunts them to a duct fate. Mech Dev 2007, 124(2):97-107.

17. Sosa-Pineda B: The gene Pax4 is an essential regulator of pancreatic beta-cell development. Mol Cells 2004, 18(3):289-294.

18. Smith SB, Ee HC, Conners JR, German MS: Paired-homeodomain transcription factor PAX4 acts as a transcriptional repressor in early pancreatic development. Mol Cell Biol 1999, 19(12):8272-8280.

19. Collombat P, Xu X, Ravassard P, Sosa-Pineda B, Dussaud S, Billestrup N, Madsen OD, Serup P, Heimberg H, Mansouri A: The ectopic expression of Pax4 in the mouse pancreas converts progenitor cells into alpha and subsequently beta cells. Cell 2009, 138(3):449-462.

20. Brun T, Franklin I, St-Onge L, Biason-Lauber A, Schoenle EJ, Wollheim CB, Gauthier BR: The diabetes-linked transcription factor PAX4 promotes \{beta\}-cell proliferation and survival in rat and human islets. J Cell Biol 2004, 167(6):1123-1135.
21. Collombat P, Hecksher-Sorensen J, Broccoli V, Krull J, Ponte I, Mundiger T, Smith J, Gruss P, Serup P, Mansouri A: The simultaneous loss of Arx and Pax4 genes promotes a somatostatin-producing cell fate specification at the expense of the alpha- and beta-cell lineages in the mouse endocrine pancreas. Development 2005, 132(13):2969-2980

22. Manousaki T, Feiner N, Begemann G, Meyer A, Kuraku S: Co-orthology of Pax4 and Pax6 to the fly eyeless gene: molecular phylogenetic, comparative genomic, and embryological analyses. Evol Dev 2011, 13(5):448-459.

23. Miura H, Yanazawa M, Kato K, Kitamura K: Expression of a novel aristaless related homeobox gene 'Arx' in the vertebrate telencephalon, diencephalon and floor plate. Mech Dev 1997, 65(1-2):99-109.

24. Binot AC, Manfroid I, Flasse L, Winandy M, Motte P, Martial JA, Peers B, Voz ML Nkx6.1 and nkx6.2 regulate alpha- and beta-cell formation in zebrafish by acting on pancreatic endocrine progenitor cells. Dev Biol 2010, 340(2):397-407.

25. Mavropoulos A, Devos N, Biemar F, Zecchin E, Argenton F, Edlund H, Motte $P$, Martial JA, Peers B: sox4b is a key player of pancreatic alpha cell differentiation in zebrafish. Dev Biol 2005, 285(1):211-223.

26. Navratilova P, Fredman D, Hawkins TA, Turner K, Lenhard B, Becker TS: Systematic human/zebrafish comparative identification of cis-regulatory activity around vertebrate developmental transcription factor genes. Dev Biol 2009, 327(2):526-540.

27. Courtney M, Pfeifer A, Al-Hasani K, Gjernes E, Vieira A, Ben-Othman N, Collombat $P$ : In vivo conversion of adult alpha-cells into beta-like cells: a new research avenue in the context of type 1 diabetes. Diabetes Obes Metab 2011, 13(Suppl 1):47-52.

28. Galy V, Gadal O, Fromont-Racine M, Romano A, Jacquier A, Nehrbass U: Nuclear retention of unspliced mRNAs in yeast is mediated by perinuclear Mlp1. Cell 2004, 116(1):63-73.

29. Rutz B, Seraphin B: A dual role for BBP/ScSF1 in nuclear pre-mRNA retention and splicing. EMBO J 2000, 19(8):1873-1886.

30. Naye F, Voz ML, Detry N, Hammerschmidt M, Peers B, Manfroid I: Essential roles of zebrafish bmp2a, fgf10, and fgf 24 in the specification of the ventral pancreas. Mol Biol Cell 2012, 23(5):945-954

31. Smith SB, Watada H, Scheel DW, Mrejen C, German MS: Autoregulation and maturity onset diabetes of the young transcription factors control the human PAX4 promoter. J Biol Chem 2000, 275(47):36910-36919.

32. Wendik B, Maier $E$, Meyer D: Zebrafish $m n x$ genes in endocrine and exocrine pancreas formation. Dev Biol 2004, 268(2):372-383.

33. Dalgin G, Ward AB, le Hao T, Beattie CE, Nechiporuk A, Prince VE: Zebrafish $\mathrm{mnx} 1$ controls cell fate choice in the developing endocrine pancreas. Development 2011, 138(21):4597-4608.

34. Westerfield M: The zebrafish book. A guide for the laboratory use of zebrafish (danio rerio). 4th edition. Eugene: Univ. of Oregon Press; 1995.

35. Kimmel CB, Ballard WW, Kimmel SR, Ullmann B, Schilling TF: Stages of embryonic development of the zebrafish. Dev Dyn 1995, 203(3):253-310

36. Hauptmann G, Gerster T: Two-color whole-mount in situ hybridization to vertebrate and Drosophila embryos. Trends Genet 1994, 10(8):266.

37. Cheesman SE, Layden MJ, Von Ohlen T, Doe CQ, Eisen JS: Zebrafish and fly Nkx6 proteins have similar CNS expression patterns and regulate motoneuron formation. Development 2004, 131(21):5221-5232.

38. Korzh V, Sleptsova I, Liao J, He J, Gong Z: Expression of zebrafish bHLH genes ngn 1 and nrd defines distinct stages of neural differentiation. Dev Dyn 1998, 213(1):92-104.

39. Argenton F, Zecchin E, Bortolussi M: Early appearance of pancreatic hormoneexpressing cells in the zebrafish embryo. Mech Dev 1999, 87(1-2):217-221.

40. Milewski WM, Duguay SJ, Chan SJ, Steiner DF: Conservation of PDX-1 structure, function, and expression in zebrafish. Endocrinology 1998, 139(3):1440-1449.

41. Pauls S, Zecchin E, Tiso N, Bortolussi M, Argenton F: Function and regulation of zebrafish $n k \times 2.2$ a during development of pancreatic islet and ducts. Dev Biol 2007, 304(2):875-890.

42. Korzh V, Edlund T, Thor S: Zebrafish primary neurons initiate expression of the LIM homeodomain protein Isl-1 at the end of gastrulation. Development 1993, 118(2):417-425.

doi:10.1186/1471-213X-12-37

Cite this article as: Djiotsa et al.: Pax4 is not essential for beta-cell differentiation in zebrafish embryos but modulates alpha-cell generation by repressing arx gene expression. BMC Developmental Biology 2012 12:37. 